\title{
Neighborhood differences in social capital in Ghent (Belgium): a multilevel approach
}

Tijs Neutens ${ }^{1,3^{*}}$, Veerle Vyncke ${ }^{2,3}$, Dieter De Winter ${ }^{2}$ and Sara Willems ${ }^{2}$

\begin{abstract}
Background: Little research has focused on the spatial distribution of social capital, despite social capital's rising popularity in health research and policy. This study examines the neighborhood differences in social capital and the determinants that explain these differences.

Methods: Five components of neighborhood social capital are identified by means of factor and reliability analyses using data collected in the cross-sectional SWING study from 762 inhabitants in 42 neighbourhoods in the city of Ghent (Belgium). Neighborhood differences in social capital are explored using hierarchical linear models with cross-level interactions.

Results: Significant neighborhood differences are found for social cohesion, informal social control and social support, but not for social leverage and generalized trust. Our findings suggest that neighborhood social capital depends on both characteristics of individuals living in the neighborhood (attachment to neighborhood) and characteristics of the neighborhood itself (deprivation and residential turnover). Our analysis further shows that neighborhood deprivation reinforces the negative effect of declining neighborhood attachment on social cohesion and informal social control.

Conclusions: This study foregrounds the importance of contextual effects in encouraging neighborhood social capital. Given the importance of neighborhood-level characteristics, it can be anticipated social capital promoting initiatives are likely to be more effective when tailored to specific areas. Second, our analyses show that not all forms of social capital are influenced by contextual factors to the same extent, implying that changes in neighborhood characteristics are conducive to, say, trust while leaving social support unaffected. Finally, our analysis has demonstrated that complex interrelationships between individual- and neighborhood-level variables exist, which are often overlooked in current work.
\end{abstract}

\section{Background}

\section{Neighborhood social capital and health}

Recent years have witnessed a burgeoning academic interest in neighborhood effects on health [1,2]. Evidence is mounting that neighborhoods with a high level of poverty and unemployment have a greater incidence of health problems [3]. Living in a deprived area is associated with a shorter life expectancy $[4,5]$, a greater presence of mental health problems [6,7] and worse self-rated health $[8,9]$.

In an effort to explain health inequalities among neighborhoods, scholars have relied on the concept of neighborhood social capital $[2,10,11]$. Neighborhood social capital is

\footnotetext{
* Correspondence: tijs.neutens@ugent.be

'Department of Geography, Ghent University, Ghent, Belgium

${ }^{3}$ Research Foundation Flanders, Brussels, Belgium

Full list of author information is available at the end of the article
}

found to be associated with mental health and reduce mortality [6,11-13] as well as detrimental health behaviors such as smoking and alcohol consumption [5,14-18]. Furthermore, research suggests that the positive association between neighborhood social capital and outcomes of wellbeing and health is stronger in deprived neighborhoods compared to non-deprived neighborhoods $[11,19,20]$.

While social capital is generally seen as conducive for health, it can also negatively impact health and well-being $[21,22]$. Strong social bonds within a group may lead to closed social networks that exclude non-members, pushing them into an outsider role. Within these closed groups (e.g. a gang) undesirable norms can be maintained. Furthermore, high levels of social capital may exert social pressure on group members as a consequence of restricting

\section{Biomed Central}

(c) 2013 Neutens et al.; licensee BioMed Central Ltd. This is an open access article distributed under the terms of the Creative Commons Attribution License (http://creativecommons.org/licenses/by/2.0), which permits unrestricted use, distribution, and reproduction in any medium, provided the original work is properly cited. 
social control and the need to conform to the prevailing social norms within the group [23].

\section{Carpiano's model of social capital}

Despite the relevance of neighborhood social capital for health, there is as yet no generally accepted definition of the concept. Nonetheless, various theoretical frameworks have been suggested in an attempt to provide useful conceptualizations of social capital (e.g., $[2,10,24])$. Most of these frameworks are inspired by the seminal work of Bourdieu [25] and/or Putnam [26,27].

A recently introduced framework of social capital is that of Carpiano [2] who defined social capital as the amount and type of resources that reside in social networks. The strength of Carpiano's framework is that it focuses on neighborhood social capital and applies the social capital theory of Bourdieu [25] but also tries to integrate the Putnamesque tradition [26,27]. Following Bourdieu, Carpiano defines social capital as the resources present in social networks. However, he additionally acknowledges the importance of neighborhood social processes such as trust and reciprocity (which he labels as 'social cohesion'), which are central to Putnam's theory as the social processes that are needed to enable the exchange of social capital. Carpiano does so in order to address the criticism that research on social capital and health is undertheorized. Furthermore, since the framework includes individual as well as neighborhood characteristics, it lends itself well to determine to what extent neighborhood differences in social capital may be explained by compositional effects (e.g. gender composition within a neighborhood) or 'true' contextual effects (e.g. neighborhood deprivation). Carpiano [2] unfolds social capital into four components: (i) social support, (ii) social leverage, (iii) informal social control and (iv) neighborhood organization participation. Social support refers to a form of social capital that people can draw upon to cope with daily problems. Social leverage helps residents to access information and advance on the socioeconomic ladder. Informal social control is the ability of residents to collectively maintain social order. Neighborhood organization participation refers to the ability of residents to organize collective activities to address neighborhood issues. In addition to these components, Carpiano includes social cohesion in the model as a distinct construct "because it represents networks and values from which social capital can be developed and used for action" ([2], p. 170). Finally, Carpiano [2] conceptualizes trust as a part of social cohesion, while other authors, among them Eriksson [24], see trust as an outcome of social capital. Social cohesion, generalized trust and the four forms of social capital can be examined separately to ascertain how spatial differences in each of these constructs can be explained by an interplay of compositional and contextual factors.

\section{Policy interest in social capital}

Alongside academic interest, the favorable health implications of social capital have also not escaped policy makers' attention. Specifically in Flanders, the regional government seeks to encourage social capital through the Pact 2020 strategy (equivalent to the European 2020 strategy), which includes among others improving community life by stimulating individuals in participating in different organizations. Investing in social capital is often considered as a strategy to promote public health and wellbeing (Vlaams Economisch Sociaal Overlegcomité, 2009) and the role of the regional level in this context is emphasized. However, policy makers should take into account the neighborhood differences in social capital across [24,28]. Since neighborhood social capital is shaped by natural, historical and cultural characteristics of neighborhoods, its relationship with health outcomes is expected to exhibit significant neighborhood differences. Therefore, the effectiveness of an intervention intended to foster social capital depends on the neighborhood where it is implemented $[24,29]$.

\section{Neighborhood differences in social capital}

Several studies describe significant regional differences in social capital, including Beugelsdijk \& Van Schaik [30] and Van Oorschot, Arts \& Gelissen [31]. Other studies were conducted at much smaller scales such as those focusing on the social capital difference between rural and urban areas [32-34] and between neighborhoods within the same city [35]. While insightful, most of these studies (ibid.) did not attempt to explain why spatial variations in social capital occur. However, a detailed insight in spatial variations of social capital and its determinants would contribute to the scarce theoretical basis on how social capital can be fostered. To that end, some scholars have recently sought to identify the socio-demographic and environmental characteristics of neighborhoods that are responsible for social capital formation.

Various studies (e.g. [2,36,37]) suggested that ethnicity is of major importance in the development of neighborhood social capital. People born in non-European countries appear to participate less in social activities and have a lower level of social capital than those born in Europe [37]. Further, the absence of trust in a neighborhood is also considered to be inimical to neighborliness and social vibrancy $[2,26]$. The absence of trust is influenced by individual factors such as age, ethnicity, being single and socio-economic status [36]. People who live in neighborhoods characterized by high-income inequality tend to exhibit low trust levels $[38,39]$. Furthermore, neighborhoods with a high percentage of elderly (65 years or older) tend to be associated with diminished levels of neighborhood social capital [36,38]. Another factor commonly associated with neighborhood social capital is physical disorder, being the level of physical stress a neighborhood suffers from as a consequence of, for 
example, littering, exhaust fumes, noise and odor nuisance. This association has been thoroughly discussed in Wilson and Kelling's [40] 'broken windows' theory as well as in Skogan's [41] 'disorder and decline' model. Generally, increasing levels of physical disorder are associated with declining levels of social cohesion and social control on deviants [42]. Finally, residential mobility is unfavorable to social capital formation as it inhibits the process of creating bonding and bridging ties [1,35]. Regarding environmental effects, neighborhood design and walkability are often put forward as being conducive to social fabric development $[43,44]$. This study seeks to integrate the above individual and neighborhood-level explanatory variables into one study and explore their effect on social capital.

\section{Research questions}

Drawing on Carpiano's model of social capital, this study uses multilevel modeling to investigate neighborhood differences in social capital in the city of Ghent (Belgium). The study explores whether social capital significantly differs between neighborhoods, and what determinants are associated to social capital at both the individual and neighborhood level. This research questions inherently refers to the debate of contextual and compositional influences of neighborhoods. Since it is very likely that both individual and neighborhood level variables influence the perception of neighborhood social capital, a simultaneous exploration of both compositional and contextual effects is needed. Multilevel modeling is the most appropriate analytical method to answer this research question. The outcome variable needs to be measured at the individual level to perform traditional multilevel analyses, which enables the identification of contextual and compositional sources of variation and accounts for the dependency in the data (i.e. individuals in neighborhoods) [45].

The paper has three specific research questions: (i) To what extent does social capital differ across neighborhoods in Ghent?; (ii) Can these neighborhood differences (partially) be explained by the characteristics of neighborhood inhabitants (compositional effect)?; (iii) Can the neighborhood differences in social capital (partially) be explained by neighborhood characteristics (contextual effect)? (iv) Does neighborhood context influence the association between social capital and its explanators?

In addressing these research questions, this paper adds to the knowledge base on neighborhood social capital in at least four important ways. First, while prior studies have largely considered social capital as a regressor for health outcomes, only few studies explicitly examined social capital as a regressand with individual and neighborhood characteristics as the regressors. Second, with some exceptions (e.g., [35]), research has primarily concentrated on regional, urban/rural and inter-city differences in social capital, while little attention has been paid to specific neighborhood differences within cities. Third, this study takes the theoretically underpinned and multidimensional framework of Carpiano [2] as a starting point and separately examines the different components that constitute neighborhood social capital. Fourth, multilevel analysis is used to investigate neighborhood differences in social capital and to disentangle compositional and contextual effects as has been called for in different studies [36,46-48]. Furthermore, this paper takes into account that previous research found a significant interaction between social capital and neigbhorhood deprivation [20,49], by actively exploring whether neighborhood context influences the assocation between social capital and it's determinants.

\section{Methods}

This study uses data gathered in the 2011-2014 Social capital and Well-being In Neighborhoods in Ghent (SWING) study. The SWING study provides information on social processes, health and socio-demographic characteristics in Ghent (Belgium) at both the individual and neighborhood level in three successive waves of data collection [50]. This study employs data of 762 neighborhood inhabitants in 42 neighborhoods in Ghent gathered during the second wave of data collection in 2012. The SWING survey uses a questionnaire, consisting of a face-to-face interview using a standardized questionnaire and a self-administered questionnaire. Sensitive questions such as questions on income, alcohol use and drug use are gathered through the self-administered questionnaire. This is done in order to minimize the risk of non-response. collected via face-to-face interviews. The response rate was $51 \%$. The survey data is complemented with data from existing, external databases from the City of Ghent (available at http://gent.buurtmonitor.be) and Ghent University, containing mostly demographic and socio-economic data.

\section{Study setting and sampling procedure}

Ghent is a medium-sized city in Belgium, $158 \mathrm{~km}^{2}$ in size, with approximately 250.000 inhabitants $\left(1.506 / \mathrm{km}^{2}\right)$. The city is divided into 201 statistical sectors. A statistical sector (henceforth referred to as 'neighborhood') comprises the smallest level at which demographic and socio-economic information is systematically gathered in Belgium and can be compared to the Anglo-Saxon census tract level. A sample of 42 neighborhoods has purposively been selected based on four criteria: (i) a minimum population size of 200 inhabitants; (ii) representativeness in terms of population density; (iii) representativeness in terms of deprivation level, based on the dynamic analysis of neighborhoods in difficulties by Vandermotten and colleagues [51]; and (iv) minimal inclusion of adjacent neighborhoods to avoid spatial autocorrelation. If bordering neighborhoods were selected, preference was given to neighborhoods separated 
by clear physical boundaries such as water bodies or highways. Figure 1 gives an overview of the selected neighborhoods in wave 2 of the SWING-study. Within each of the 42 selected neighborhoods a representative sample of inhabitants was selected from the municipal registry, stratified based on age, gender and nationality. For each selected inhabitant, three substitutes were selected within the same category with regard to age, gender and origin. Respondents who could not be reached or refused to participate were replaced by a randomly selected respondent from the corresponding age, gender and ethnic stratum, striving for a total of 20 inhabitants per neighbourhood. Persons who were younger than 18 years old at the time of the survey, those who had insufficient knowledge of the Dutch language and those who lived in a residential setting (e.g. home for the elderly, prison, etc.) were excluded from the survey [50].

In addition to the questionnaire for the inhabitants, information about neighbourhood social capital has also been obtained from key informants through a separate questionnaire. Key informants are people who work in one of the selected neighbourhoods and can observe what is happening in these neighbourhoods. They often have on average more knowledge about the social processes under study and can provide more useful and less biased information. Previous research has demonstrated that this method is able to create ecologically reliable and valid measures of neighbourhood social processes [50]. In total, 638 key informants were surveyed. It should be noted that the key informants have not been recruited from the set of inhabitants as to avoid bias in the level of neighborhood social capital. In other words, none of the 638 key informants is one of the 762 inhabitants.

\section{Dependent variables}

The operationalization of the dependent variable, neighborhood social capital, is based on the multidimensional and theoretical framework provided by Carpiano [2]. The dependent variables include informal social control, social support, social leverage, social cohesion, and generalized trust in a neighborhood. Although neighborhood organization participation is included in the theoretical framework of Carpiano, this concept will not be considered in the analyses as no data was available on this component of social capital.

The components of neighborhood social capital are measured using a 4-point or 5-point Likert scale, except for generalized trust which is measured using a Visual Analogue Scale (VAS) between 0 and 10 (Table 1). Item responses were summed to create a single scale for each component of social capital, with a higher score referring to higher levels of social capital. The maximum score for each social capital component thus depends on the number of measurement items. The maximum score for social cohesion, informal social control, social support, social leverage and generalized trust are 20, 30, 20, 25 and 30, respectively. Results of the factor analyses (forced one-factor solutions in an exploratory principal axis factoring analysis) and reliability analyses used to construct the final scales are reported in Table 1. The social capital scales are all unidimensional, with acceptable to good internal consistency. Cronbach's $\alpha$ ranges from 0.79 to 0.88 , which are situated above the generally accepted cut-off values of 0.70-0.80.

\section{Independent variables}

Relevant independent variables at both the individual and neighborhood level are selected based on the relevant literature. At the individual level, this study takes the following variables into account: age, gender, ethnicity, having a partner and educational attainment. Each of these variables has been dichotomized. Age is dichotomized with persons younger than 65 years old being the reference category. This classification aligns with prior work [36,38], indicating that the $65+$ age cohort tends to dispose of less social capital than their younger counterparts. The reference category for gender are men. Regarding ethnicity, respondents are considered to have a different ethnic background if one or both of the parents do not have the Belgian nationality (having the Belgian nationality served as the reference category). For 'having a partner', those with a partner served as the reference category. Educational attainment is dichotomized with a lower degree (degree up to the third year of secondary school) serving as the reference category. Since the correlation of educational attainment with income is higher $(r=0.350)$ than with other variables and income has a high number of missing values $(n=81)$, income has not been included as an explanatory variable. ${ }^{a} \mathrm{Fi}-$ nally, two dummy variables on residential length (with people living in the neighborhood for at least 5 years serving as the reference category) and neighborhood attachment (reference category: high neighborhood attachment) are included. It is hypothesized that a short residential stay (i.e. less than 5 years) negatively affects social capital at the individual level, while neighborhood attachment is assumed to positively influence the presence of neighborhood social capital (see also [2,24]). People were asked to report to what extent they feel attached to their neighborhood, using a 5-point Likert scale ranging from 'strongly disagree' to 'strongly agree'. Those who agreed with feeling attached to their neighborhood served as the reference category.

At the neighborhood level, four variables are included in the analyses: neighborhood deprivation, percentage of elderly (65 years or older), residential mobility and physical disorder. To determine whether or not a neighborhood is deprived, a classification made by Vandermotten 


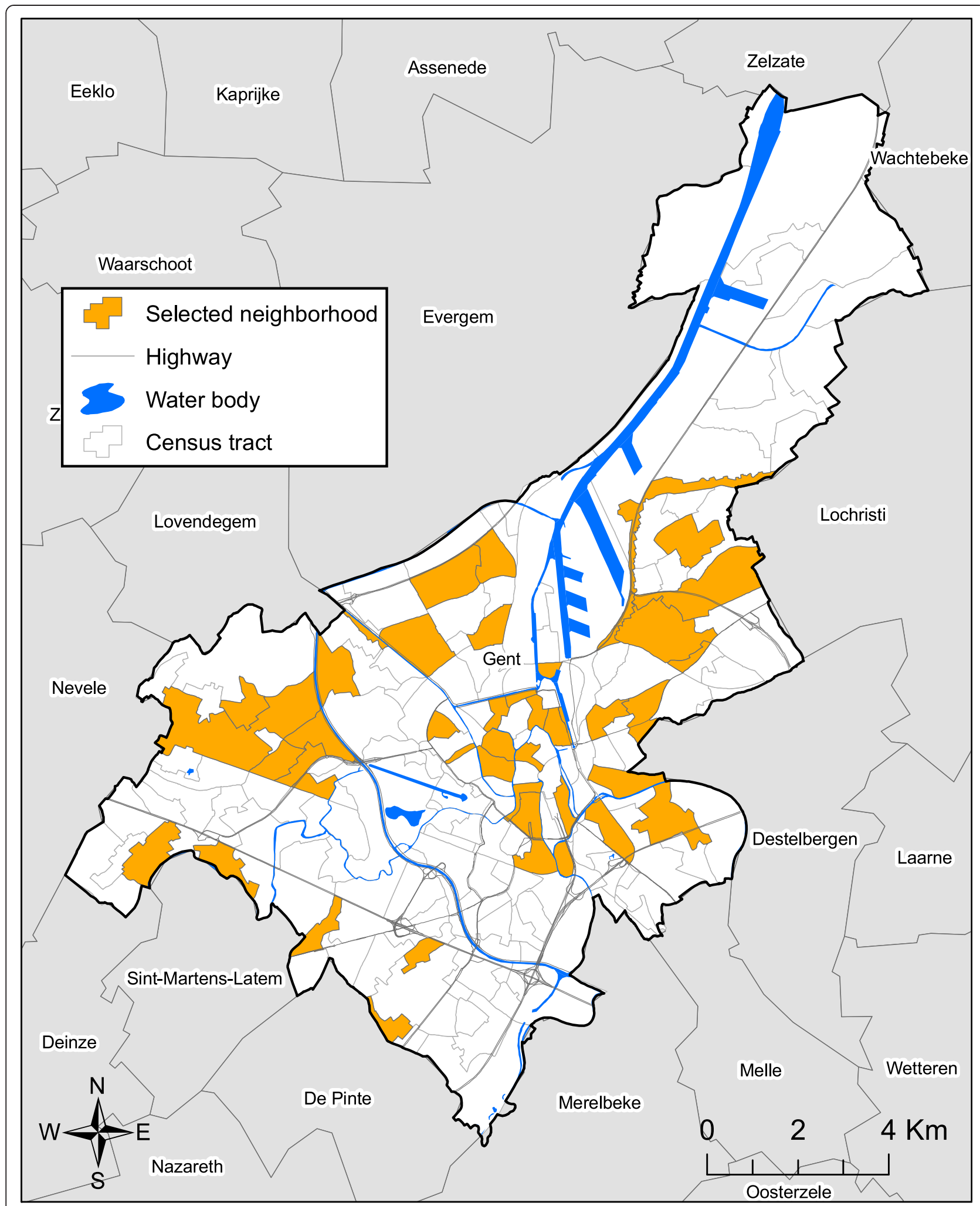

Figure 1 SWING-study wave 2: study area and selected neighborhoods. 
Table 1 Five components of neighborhood social capital: overview of indicators and results of factor and reliability analyses

Summative scale and individual items
Social cohesion
1. People around here are willing to help their neighbors
3. Phis is a close-knit neighborhood
4. Contacts between inhabitants in this neighborhood are generally positive

\section{Informal social control}

How likely is it that you could count on neighbors intervening when...

1. Children were skipping school and hang out on a street corner

2. Children were spray-painting graffiti on a local building

3. Children were showing disrespect to an adult

4. A fight breaks out in front of their house

5. Children were making too much racket

6. Children are using soft drugs (smoking weed, hasj, etc.)

\section{Social support}

1. People in this neighborhood give or advice to each other (emotional/informational support).

2. People in this neighborhood give material aid and assistance to each other (tangible support)

3. People in this neighborhood show affection for each other (affectionate support).

4. People in this neighborhood can call on each other to do enjoyable things (positive social interaction).

\section{Social Leverage}

How often does it happen that people in this neighborhood give each other advice on...
1. Child rearing
2. Job openings
3. Welfare and other benefits
4. Education and courses
5. Finances

\section{Generalized Trust}

Most people in this neighborhood can be trusted

Most people in this neighborhood would try to take advantage of you

Most people in this neighborhood try to be helpful

\section{Coding}

Factor loadings (1) \&

Cronbach's Alpha (2)

$0.83(2)$

Strongly Agree $\rightarrow$ Strongly

Disagree**

Strongly Agree $\rightarrow$ Strongly $\quad 0.71(1)$

Disagree**

Strongly Agree $\rightarrow$ Strongly $\quad 0.69(1)$

Disagree**

Strongly Agree $\rightarrow$ Strongly Disagree** $^{* *}$

$0.87(2)$

$$
\begin{array}{ll}
\text { Very Likely } \rightarrow \text { Very Unlikely** } & 0.69(1) \\
\text { Very Likely } \rightarrow \text { Very Unlikely** } & 0.74(1) \\
\text { Very Likely } \rightarrow \text { Very Unlikely** } & 0.74(1) \\
\text { Very Likely } \rightarrow \text { Very Unlikely** } & 0.75(1) \\
\text { Very Likely } \rightarrow \text { Very Unlikely** } & 0.70(1) \\
\text { Very Likely } \rightarrow \text { Very Unlikely** } & 0.74(1) \\
\text { Never } \rightarrow \text { Often* } & \mathbf{0 . 7 9 ( 2 )} \\
\text { Never } \rightarrow \text { Often* } & 0.70(1) \\
\text { Never } \rightarrow \text { Often* } & 0.80(1) \\
\text { Never } \rightarrow \text { Often* } & 0.61(1)
\end{array}
$$

$0.88(2)$

$$
\begin{array}{ll}
\text { Never } \rightarrow \text { Often* } & 0.71(1) \\
\text { Never } \rightarrow \text { Often* } & 0.80(1) \\
\text { Never } \rightarrow \text { Often* } & 0.77(1) \\
\text { Never } \rightarrow \text { Often* } & 0.81(1) \\
\text { Never } \rightarrow \text { Often* } & 0.74(1) \\
& \mathbf{0 . 7 6 ( 2 )} \\
0 \rightarrow 10 & 0.71(1) \\
0 \rightarrow 10 & 0.75(1) \\
0 \rightarrow 10 & 0.68(1)
\end{array}
$$

Note: * 4- point Likert scale; **5- point Likert scale; original questionnaire in Dutch.

et al. [51] is used. These authors created an index which defines deprivation based on the accumulative presence of 22 unfavorable indicators related to factors such as income, education and housing. Non-deprived neighborhoods are considered as the reference category, since we are interested in the effect of socio-economic deprivation.

Since income and ethnicity are already implicitly covered by this multidimensional index of deprivation, these concepts are not separately included in the analyses for reasons of multicollinearity. Residential mobility of a neighborhood is measured by means of turnover (i.e. number of migration movements per 1000 inhabitants). It is hypothesized that high turnover erodes neighborhood social capital as it inhibits social ties to be adequately formed [1]. Although neighborhood design, measured in terms of land use mix and walkability, could have an effect on 
neighborhood social capital (see e.g., $[43,44]$ ), this variable highly correlated with turnover $(r=0.823)$ and is therefore not taken up in the statistical analysis. To account for the age composition of neighborhoods, the percentage of elderly in the neighborhood is included to determine whether a neighborhood with a high level of people aged $65+$ tends to dispose of less social capital (reference category: people younger than 65). Physical disorder was represented by a four-item Likert scale. Key informants were asked (on a five-point scale) how often they have observed each of the following four occurrences in their neighborhood: (1) 'litter on the streets', (2) 'exhaust gases', (3) 'noise pollution', and (4) 'bad smell'. The scale has an alpha of 0.74. The scale is constructed following a two-step procedure ([52]). First, summative scales were calculated at the individual (key-informant) level. Consequently, these individual scores were aggregated to the neighborhood level. This variable is the only one that uses the data provided by the key informants.

\section{Analysis}

SPSS Statistics 21 is used for data preparation and exploratory analyses. To assess the geographical variation of neighborhood social capital, multilevel linear regression analyses are fitted using maximum likelihood estimation in MLWIN 2.26. Multilevel analysis accounts for the nested data structure of people within neighborhoods and allows for estimation of (i) the effect of individual and neighborhood level factors on neighborhood social capital (fixed part) and (ii) the variation in social capital among neighborhoods that cannot be accounted for by the included predictors (random part) [11,36,47]. Furthermore, multilevel modeling enables insight into the extent to which potential neighborhood differences in social capital are due to either individual-level characteristics (compositional variation) or characteristics of the neighborhoods themselves (contextual variation) [36,47]. Due to a high correlation between the different components of neighborhood social capital (ranging from 0.158 to 0.625 ) and to enable a differentiated analysis, models were fitted for each social capital component separately.

A three-step sequential strategy is used to run the multilevel models. First, a null model (model 0) is fitted, without any level 1 or level 2 predictors. This model serves as a benchmark to which the other models are compared, following the difference in deviance test. Model 1a includes only individual-level variables to determine to what extent differences in neighborhood social capital can be explained as a compositional effect. Model 2a additionally includes neighborhood variables and identifies the neighborhood-level variables that explain the geographic variation of neighborhood social capital. Parsimonious models, that contain only the individual and neighborhood predictors that are significantly associated with neighborhood social capital, are composed in order to maximize statistical power (models $1 \mathrm{~b}$ and $2 \mathrm{~b}$ ). To estimate whether the explanatory variables have a different effect in different neighborhood settings, models that allow for a random slope of the significant predictor variables are explored. Finally, a cross-level interaction is modeled to study the interaction between neighborhood deprivation and variables influencing neighborhood social capital. Since some research suggests an interaction between neighborhood social capital and deprivation, we want to explore if neighborhood deprivation affects the relationship between social capital and the independent variables.

\section{Results}

The characteristics of the 762 respondents are listed in Table 2. These characteristics closely mirror those of the actual population of Ghent (see Hardyns et al., [50] for a

Table 2 Sample characteristics

\begin{tabular}{|c|c|c|c|c|c|}
\hline & $\mathbf{N}$ & $\%$ & $\mathrm{~m}$ & sd & Range (Min - Max) \\
\hline \multicolumn{6}{|l|}{ Individual level } \\
\hline Age (in years) & & & 48.65 & 19.02 & 77 (18-95) \\
\hline 65 years or older & 180 & $21.3 \%$ & & & \\
\hline Male & 370 & $48.6 \%$ & & & \\
\hline Female & 392 & $51.4 \%$ & & & \\
\hline Single & 199 & $26.1 \%$ & & & \\
\hline Not Belgian & 91 & $11.9 \%$ & & & \\
\hline Low education level & 130 & $17.1 \%$ & & & \\
\hline Short residential stay (5 years or less) & 226 & $29.7 \%$ & & & \\
\hline \multicolumn{6}{|l|}{ Neighborhood level } \\
\hline Deprivation & 9 & $21.5 \%$ & & & \\
\hline Turnover (per 1000 inhabitants) & 42 & & 241.32 & 136.64 & $469.51(94.05-564.01)$ \\
\hline Physical disorder & 42 & & 14.31 & 2.71 & $11.25(8.75-20)$ \\
\hline
\end{tabular}

$\mathrm{N}=$ absolute number, $\mathrm{m}=$ mean, $\mathrm{sd}=$ standard deviation 


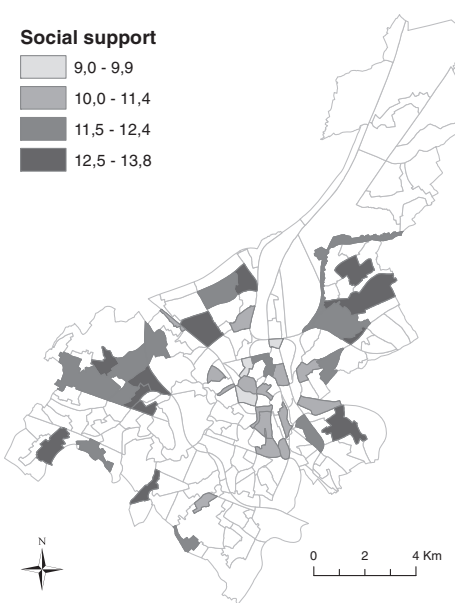

(a)

$$
\begin{aligned}
& \text { Informal social control } \\
& \begin{array}{|l|l}
\hline & 12,7-13,5 \\
13,6-17,8 \\
17,9-20,1 \\
20,2-23,0
\end{array}
\end{aligned}
$$

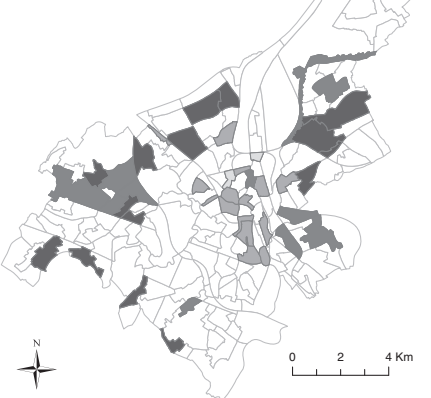

(c)

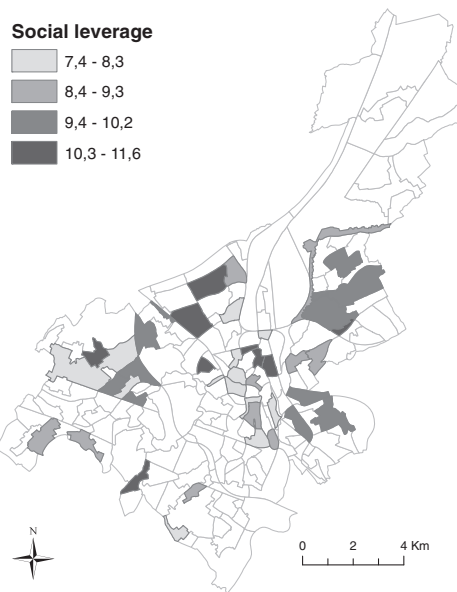

(b)

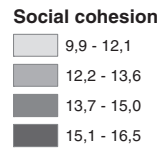

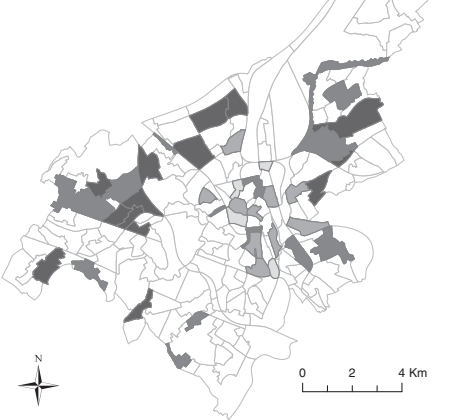

(d)

$$
\begin{array}{|}
\text { Generalized trust } \\
\begin{array}{|c|}
\hline 12,7-15,3 \\
15,4-17,2 \\
17,3-18,8 \\
18,9-21,3
\end{array} \\
\hline
\end{array}
$$

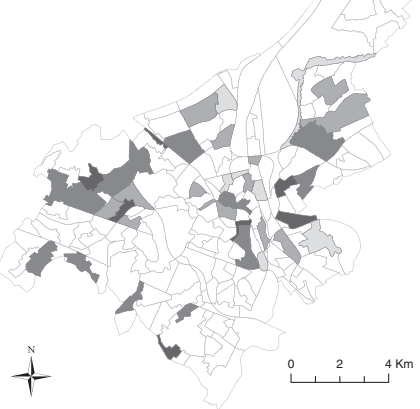

(e)

Figure 2 Differences in the neighborhood average of individual scores on the scales of (a) social support, (b) social leverage, (c) informal social support, (d) social cohesion and (e) generalized trust. 
Table 3 Fixed and random parameters of the social cohesion multilevel models

\begin{tabular}{|c|c|c|c|c|c|}
\hline & Model 0 & Model 1a & Model 1b & Model 2a & Model 2b \\
\hline & $\beta(S E)$ & $\beta(\mathrm{SE})$ & $\beta(\mathrm{SE})$ & $\beta$ (SE) & $\beta$ (SE) \\
\hline \multicolumn{6}{|l|}{ Fixed effects } \\
\hline Constant & $14.241(0.215)^{* * *}$ & $14.903(0.246)^{* * *}$ & $14.920(0.199)^{* * *}$ & $15.038(0.219)^{* * *}$ & $15.121(0.170)^{* * * *}$ \\
\hline \multicolumn{6}{|l|}{ Level 1} \\
\hline Female & & $-0.031(0.199)$ & & $-0.034(0.198)$ & \\
\hline 65 years or older & & $0.086(0.257)$ & & $0.050(0.256)$ & \\
\hline Low education level & & $-0.001(0.288)$ & & $0.058(0.283)$ & \\
\hline Single & & $-0.572(0.231)^{*}$ & $-0.527(0.228)^{*}$ & $-0.493(0.230)^{*}$ & $-0.491(0.226)^{*}$ \\
\hline Not Belgian & & $0.076(0.329)$ & & $0.276(0.329)$ & \\
\hline Weak neighborhood attachment & & $-1.941(0.236)^{* * *}$ & $-1.962(0.233)^{* * *}$ & $-1.891(0.233)^{* * *}$ & $-1.901(0.230)^{* * *}$ \\
\hline$<5$ years of residence & & $-0.009(0.236)$ & & $0.076(0.235)$ & \\
\hline \multicolumn{6}{|l|}{ Level 2} \\
\hline Deprived neighborhood & & & & $-0.960(0.337)^{*}$ & $-0.977(0.351)^{* *}$ \\
\hline Percentage of elderly & & & & $-0.156(0.142)$ & \\
\hline Turnover & & & & $-0.552(0.173)^{* * *}$ & $-0.557(0.143)^{* * *}$ \\
\hline Physical disorder & & & & $-0.188(0.177)$ & \\
\hline \multicolumn{6}{|l|}{ Random effects } \\
\hline \multicolumn{6}{|l|}{ Level 1} \\
\hline Constant & $7.852(0.414)^{* * *}$ & $7.244(0.384)^{* * *}$ & $7.246(0.383)^{* * *}$ & $7.232(0.383)^{* * *}$ & $7.253(0.383)^{* * *}$ \\
\hline \multicolumn{6}{|l|}{ Level 2} \\
\hline Constant & $1.510(0.425)^{* * *}$ & $0.964(0.300)^{* * *}$ & $0.944(0.295)^{* * *}$ & $0.247(0.143)$ & $0.298(0.154)$ \\
\hline Intraclass correlation & 0.161 & 0.117 & 0.115 & 0.033 & 0.039 \\
\hline Log likelihood & 3795,593 & 3688,729 & 3714,429 & 3656,402 & 3685,974 \\
\hline$\Delta$ Log likelihood $(\Delta d f)$ & & 106,864 & 81,164 & 139,191 & 109,619 \\
\hline$P$ & & $<0.001$ & $<0.001$ & $<0.001$ & $<0.001$ \\
\hline
\end{tabular}

Note: ${ }^{*} \mathrm{p}<0.05,{ }^{* *} \mathrm{p}<0.01,{ }^{* * *} \mathrm{p}<0.001$.

Model 0: null model without level 1 and level 2 variables; Model 1a: model with only level 1 variables; Model 1b: parsimonious model with only level 1 variables; Model 2a: model with level 1 and level 2 variables; Model 2b: parsimonious model with level 1 and level 2 variables.

statistical analysis of the representativeness of the sample).

Figure 2 illustrates neighborhood differences for each of the five social capital scales using Jenks' [53] natural breaks classification. To create this figure, the summative scales which reflect inhabitants perceptions on neighborhood social capital are aggregated to obtain a neighborhood level score for each of the components of social capital. The neighborhood averages equal $14.2( \pm 1.4$, [9.9,16.6]), 18.9 ( $\pm 2.4,[12.7,23.0]), 11.7( \pm 1.1,[9,13.8]), 9.3( \pm 1.2,[11.6,7.4])$ and $17.3( \pm 1.9,[12.7,21.3])$ for social cohesion, informal social control, social support, social leverage and generalized trust, respectively.

The results of the multilevel models are summarized below. Each component of neighborhood social capital is reported separately in Tables 3, 4, 5, 6 and 7. All social capital components significantly differ between neighborhoods, exept for social leverage. However, adding neighborhood determinants in the analyses nullifies the signficant neighborhood variation in social capital.The intraclass correlation coefficient (ICC) in the null model for the different components of neighborhood social capital ranges from 4.6 (social leverage) to $16.1 \%$ (social cohesion), which suggest that a modest part of the variation in neighborhood social capital can be attributed to the neighborhood level.

\section{Individual variables and social capital}

The first model analyses the association of different individual characteristics with neighborhood social capital. Having a weak neighborhood attachment is associated with lower levels of all components of neighborhood social capital. Also, being single is associated with lower levels of social cohesion and social support. The $65+$ cohort has more difficulty in using social leverage relative to their younger counterparts. Finally, results show that a low 
Table 4 Fixed and random parameters of the informal social control multilevel models

\begin{tabular}{|c|c|c|c|c|c|}
\hline & Model 0 & Model 1a & Model 1b & Model 2a & Model 2b \\
\hline & $\beta(S E)$ & $\beta(S E)$ & $\beta(S E)$ & $\beta(\mathrm{SE})$ & $\beta(S E)$ \\
\hline \multicolumn{6}{|l|}{ Fixed effects } \\
\hline Constant & $18.883(0.369)^{* * *}$ & $19.341(0.463)^{* * *}$ & $19.358(0.360)^{* * *}$ & $19.569(0.401)^{* * *}$ & $19.719(0.283)^{* * * *}$ \\
\hline \multicolumn{6}{|l|}{ Level 1} \\
\hline Female & & $0.268(0.370)$ & & $0.246(0.368)$ & \\
\hline 65 years or older & & $-0.805(0.476)$ & & $-0.884(0.475)$ & \\
\hline Low education level & & $0.385(0.536)$ & & $0.330(0.526)$ & \\
\hline Single & & $0.283(0.430)$ & & $0.429(0.427)$ & \\
\hline Not Belgian & & $-0.894(0.610)$ & & $-0.461(0.610)$ & \\
\hline Weak neighborhood attachment & & $-1.858(0.439)^{* * *}$ & $-1.725(0.434)^{* * *}$ & $-1.775(0.432)^{* * *}$ & $-1.631(0.428)^{* * *}$ \\
\hline$<5$ years of residence & & $0.267(0.439)$ & & $0.397(0.436)$ & \\
\hline \multicolumn{6}{|l|}{ Level 2} \\
\hline Deprived neighborhood & & & & $-1.479(0.681)^{*}$ & $-1.644(0.624)^{*}$ \\
\hline Percentage of elderly & & & & $-0.268(0.256)$ & \\
\hline Turnover & & & & $-1.236(0.312)^{* * *}$ & $-1.224(0.254)^{* * *}$ \\
\hline Physical disorder & & & & $-0.329(0.318)$ & \\
\hline \multicolumn{6}{|l|}{ Random effects } \\
\hline \multicolumn{6}{|l|}{ Level 1} \\
\hline Constant & $25.541(1.348)^{* * *}$ & $24.885(1.319)^{* * *}$ & $25.277(1.336)^{* * *}$ & $6.667(0.344)^{* * *}$ & $25.263(1.335)^{* * *}$ \\
\hline \multicolumn{6}{|l|}{ Level 2} \\
\hline Constant & $4.277(1.256)^{* * *}$ & $3.551(1.083)^{* * *}$ & $3.429(1.057)^{* * *}$ & $0.000(0.000)$ & $0.804(0.487)$ \\
\hline Intraclass correlation & 0.143 & 0.125 & 0.119 & 0.000 & 0.031 \\
\hline Log likelihood & 4671,624 & 4603,412 & 4651,175 & 4567,579 & 4617,973 \\
\hline$\Delta$ Log likelihood $(\Delta d f)$ & & 68,212 & 20,449 & 104,045 & 53,651 \\
\hline$P$ & & $<0.001$ & $<0.001$ & $<0.001$ & $<0.001$ \\
\hline
\end{tabular}

Note: ${ }^{*} \mathrm{p}<0.05,{ }^{* *} \mathrm{p}<0.01,{ }^{* * *} \mathrm{p}<0.001$.

Model 0: null model without level 1 and level 2 variables; Model 1a: model with only level 1 variables; Model 1b: parsimonious model with only level 1 variables; Model 2a: model with level 1 and level 2 variables; Model 2b: parsimonious model with level 1 and level 2 variables.

educational attainment contributes to lower trust levels. The association between these individual predictors and neighborhood social capital remains significant when neighborhood variables are accounted for (model $2 \mathrm{a}$ and $2 \mathrm{~b}$ ). The only exceptions are the relationship between age and social leverage and the relationship between being single and social support. Gender and short residential stay are not related to the presence of neighborhood social capital. Finally, none of the random slope models show a significant slope variance, they will therefore not be discussed. Results of these models are available from the author upon request.

\section{Neighborhood variables and social capital}

Results show that neighborhood deprivation is associated with lower levels of neighborhood social cohesion and informal social control. Furthermore, having a high residential turnover at the neighborhood level is negatively related to all components of neighborhood social capital after taking the socio-demographic composition of the neighborhood into account, except for generalized trust. Also, after controlling for compositional effects, neighborhoods with high levels of turnover tend to exhibit less neighborhood social capital, except in the form of generalized trust. None of the neighborhood variables are significantly associated to levels of generalized trust, while neighborhood turnover is only marginally significantly associated to neighborhood social leverage.

\section{Cross-level interactions}

Finally, cross-level interactions were examined between neighborhood deprivation and the significant individual determinants of neighborhood social capital. A significant interaction effect between neighborhood deprivation and neighborhood attachment was identified for social cohesion and for informal social control $(\beta=-1.41, \mathrm{p}=0.003$ and $\beta=-2.37, p=0.007)$. These results indicate that living 
Table 5 Fixed and random parameters of the social support multilevel models

\begin{tabular}{|c|c|c|c|c|c|}
\hline & Model 0 & Model 1a & Model 1b & Model 2a & Model 2b \\
\hline & $\beta(S E)$ & $\beta(\mathrm{SE})$ & $\beta(\mathrm{SE})$ & $\beta$ (SE) & $\beta$ (SE) \\
\hline \multicolumn{6}{|l|}{ Fixed effects } \\
\hline Constant & $11.691(0.169)^{* * *}$ & $12.465(0.207)^{* * *}$ & $12.317(0.160)^{* * *}$ & $12.382(0.190)^{* * *}$ & $12.193(0.117)^{* * *}$ \\
\hline \multicolumn{6}{|l|}{ Level 1} \\
\hline Female & & $-0.069(0.191)$ & & $-0.064(0.190)$ & \\
\hline 65 years or older & & $-0.183(0.246)$ & & $-0.197(0.244)$ & \\
\hline Low education level & & $-0.102(0.273)$ & & $-0.052(0.266)$ & \\
\hline Single & & $-0.462(0.221)^{*}$ & $-0.464(0.217)^{*}$ & $-0.350(0.219)$ & \\
\hline Not Belgian & & $0.153(0.312)$ & & $0.336(0.313)$ & \\
\hline Weak neighborhood attachment & & $-1.816(0.224)^{* * *}$ & $-1.839(0.220)^{* * *}$ & $-1.769(0.219)^{* * *}$ & $-1.787(0.216)^{* * *}$ \\
\hline$<5$ years of residence & & $-0.276(0.224)$ & & $-0.149(0.223)$ & \\
\hline \multicolumn{6}{|l|}{ Level 2} \\
\hline Deprived neighborhood & & & & $-0.115(0.288)$ & \\
\hline Percentage of elderly & & & & $-0.175(0.107)$ & \\
\hline Turnover & & & & $-0.567(0.133)^{* *}$ & $-0.618(0.102)^{* * *}$ \\
\hline Physical disorder & & & & $-0.194(0.134)$ & \\
\hline \multicolumn{6}{|l|}{ Random effects } \\
\hline \multicolumn{6}{|l|}{ Level 1} \\
\hline Constant & $7.163(0.378)^{* * *}$ & $6.707(0.355)^{* * *}$ & $6.688(0.353)^{* * *}$ & $6.677(0.344)^{* * *}$ & $6.719(0.354)^{* * *}$ \\
\hline \multicolumn{6}{|l|}{ Level 2} \\
\hline Constant & $0.794(0.261)^{* * *}$ & $0.381(0.166)^{*}$ & $0.410(0.172)^{*}$ & $0.000(0.000)$ & $0.055(0.095)$ \\
\hline Intraclass correlation & 0.100 & 0.054 & 0.058 & 0.000 & 0.008 \\
\hline Log likelihood & 3708,957 & 3608,963 & 3632,345 & 3576,124 & 3615,077 \\
\hline$\Delta$ Log likelihood $(\Delta d f)$ & & 99,994 & 76,612 & 132,833 & 93,880 \\
\hline$P$ & & $<0.001$ & $<0.001$ & $<0.001$ & $<0.001$ \\
\hline
\end{tabular}

Note: ${ }^{*} \mathrm{p}<0.05,{ }^{* *} \mathrm{p}<0.01,{ }^{* * *} \mathrm{p}<0.001$.

Model 0: null model without level 1 and level 2 variables; Model 1a: model with only level 1 variables; Model 1b: parsimonious model with only level 1 variables; Model 2a: model with level 1 and level 2 variables; Model 2b: parsimonious model with level 1 and level 2 variables.

in a deprived neighborhood reinforces the negative effect of declining neighborhood attachment on social cohesion and informal social control. None of the other variables show significant interaction effects.

\section{Discussion}

The analysis shows that most of the researched components of social capital significantly vary across neighborhoods in Ghent. Overall, the contextual effect is modest but persistent after adjusting the null model for individual characteristics. In the variance components models, the ICC was highest for social cohesion, informal social control and social support. This shows that the proportion of the variance in neighborhood social capital, which can be attributed to the neighborhood level, is largest for these components of social capital. These findings align with a recent study by Baum et al. [54] who focused on health differences between neighborhoods and found significant between-neighborhood variation in social cohesion. They contend that social cohesion and informal social control are often linked together in the sense that communities with a strong sense of social cohesion are more able to exert informal social control to establish and maintain norms and reduce crime.

A clear difference is found between the different components of neighborhood social capital. Social cohesion and informal social control are affected by both individual and neighborhood aspects (contextual effect above a compositional effect), while social leverage and generalized trust are only explained by individual aspects (compositional effect). These findings suggest that the variation of social capital across neighborhoods can be seen as a contextual effect, especially for social cohesion and informal social control, but that individual-level predictors remain significant. By not including the relevant individual predictors, we could misinterpret the fixed part of a two-level statistical model [55]. 
Table 6 Fixed and random parameters of the social leverage multilevel models

\begin{tabular}{|c|c|c|c|c|c|}
\hline & Model 0 & Model 1a & Model 1b & Model 2a & Model 2b \\
\hline & $\beta(S E)$ & $\beta(\mathrm{SE})$ & $\beta(\mathrm{SE})$ & $\beta(S E)$ & $\beta$ (SE) \\
\hline \multicolumn{6}{|l|}{ Fixed effects } \\
\hline Constant & $9.291(0.178)^{* * *}$ & $10.116(0.261)^{* * *}$ & $9.972(0.194)^{* * *}$ & $9.918(0.265)^{* * *}$ & $9.969(0.189)^{* * *}$ \\
\hline \multicolumn{6}{|l|}{ Level 1} \\
\hline Female & & $-0.348(0.257)$ & & $-0.348(0.257)$ & \\
\hline 65 years or older & & $-0.743(0.331)^{*}$ & $-0.905(0.304)^{* *}$ & $-0.679(0.333)$ & \\
\hline Low education level & & $-0.525(0.364)$ & & $-0.579(0.363)$ & \\
\hline Single & & $0.087(0.297)$ & & $0.196(0.297)$ & \\
\hline Not Belgian & & $0.559(0.416)$ & & $0.605(0.424)$ & \\
\hline Weak neighborhood attachment & & $-1.736(0.298)^{* * *}$ & $-1.775(0.296)^{* * *}$ & $-1.717(0.300)^{* * *}$ & $-1.716(0.297)^{* * *}$ \\
\hline$<5$ years of residence & & $-0.013(0.299)$ & & $0.100(0.302)$ & \\
\hline \multicolumn{6}{|l|}{ Level 2} \\
\hline Deprived neighborhood & & & & $0.557(0.424)$ & \\
\hline Percentage of elderly & & & & $-0.292(0.158)$ & \\
\hline Turnover & & & & $-0.418(0.195)^{*}$ & $-0.262(0.154)$ \\
\hline Physical disorder & & & & $-0.150(0.197)$ & \\
\hline \multicolumn{6}{|l|}{ Random effects } \\
\hline \multicolumn{6}{|l|}{ Level 1} \\
\hline Constant & $12.649(0.672)^{* * *}$ & $11.975(0.639)^{* * *}$ & $12.057(0.642)^{* * *}$ & $11.975(0.639)^{* * *}$ & $12.056(0.642)^{* * *}$ \\
\hline \multicolumn{6}{|l|}{ Level 2} \\
\hline Constant & $0.612(0.291)^{*}$ & $0.329(0.222)$ & $0.367(0.231)$ & $0.130(0.179)$ & $0.300(0.216)$ \\
\hline Intraclass correlation & 0.046 & 0.027 & 0.030 & 0.011 & 0.019 \\
\hline Log likelihood & 4057,65 & 3969,854 & 4003,094 & 3960,668 & 4000,306 \\
\hline$\Delta$ Log likelihood $(\Delta d f)$ & & 87,796 & 54,556 & 96,982 & 57,344 \\
\hline$P$ & & $<0.001$ & $<0.001$ & $<0.001$ & $<0.001$ \\
\hline
\end{tabular}

Note: ${ }^{*} \mathrm{p}<0.05,{ }^{* *} \mathrm{p}<0.01,{ }^{* * *} \mathrm{p}<0.001$.

Model 0: null model without level 1 and level 2 variables; Model 1a: model with only level 1 variables; Model 1b: parsimonious model with only level 1 variables; Model 2a: model with level 1 and level 2 variables; Model 2b: parsimonious model with level 1 and level 2 variables.

At the individual level, the strongest predictor for neighborhood social capital is the level of neighborhood attachment. Weak neighborhood attachment is associated with lower levels of neighborhood social capital and this holds for all aspects of social capital. Low levels of neighborhood attachment disconnect people from networks that possess beneficial resources and provide social support in times of hardship [24]. Further, being single is significantly related with perceptions of neighborhood social support. This tends to suggest that people with a partner have more social ties and better access to social networks through their partner. This finding echoes that of Subramanian, Lochner and Kawachi [36] who observed that divorced people experience lower levels of social capital. Additionally, low educational attainment is associated with lower levels of generalized trust and people aged 65+ report lower levels of social leverage.

At the neighborhood level, neighborhood deprivation and residential turnover are the strongest predictors for neighborhood social capital. Residential turnover was significant for all but one component of social capital (i.e. generalized trust). The importance of residential turnover has also been highlighted in other research $[1,35]$. Creating social ties and forming social capital takes time and high residential mobility within a neighborhood strongly inhibits this process [1]. An additional contextual explanatory variable for social cohesion and informal social control is neighborhood deprivation. A possible explanation is that a deprived neighborhood setting has downward leveling norms and, consequently, a higher incidence of crime [56]. People feel less safe, resulting in a less socially cohesive neighborhood and the absence of norms and values that give rise to informal social control $[43,54]$. As opposed to other studies that found age distribution to be associated with associational involvement [38] and trust [36], age distribution, measured in terms of the percentage of elderly within a neighborhood, could only be associated with social 
Table 7 Fixed and random parameters of the generalized trust multilevel models

\begin{tabular}{|c|c|c|c|c|c|}
\hline & Model 0 & Model 1a & Model 1b & Model 2a & Model 2b \\
\hline & $\beta$ (SE) & $\beta$ (SE) & $\beta$ (SE) & $\beta(\mathrm{SE})$ & $\beta(S E)$ \\
\hline \multicolumn{6}{|l|}{ Fixed effects } \\
\hline Constant & $17.263(0.292)^{* * *}$ & $18.220(0.427)^{* * *}$ & $18.072(0.318)^{* * *}$ & $18.418(0.450)^{* * *}$ & \\
\hline \multicolumn{6}{|l|}{ Level 1} \\
\hline Female & & $-0.336(0.400)$ & & $-0.333(0.400)$ & \\
\hline 65 years or older & & $0.440(0.514)$ & & $0.402(0.517)$ & \\
\hline Low education level & & $-1.356(0.570)^{*}$ & $-1.173(0.541)^{*}$ & $-1.275(0.573)^{*}$ & \\
\hline Single & & $-0.425(0.461)$ & & $-0.435(0.463)$ & \\
\hline Not Belgian & & $0.330(0.652)$ & & $0.487(0.664)$ & \\
\hline Weak neighborhood attachment & & $-2.219(0.466)^{* * *}$ & $-2.234(0.459)^{* * *}$ & $-2.125(0.471)^{* * *}$ & \\
\hline$<5$ years of residence & & $0.050(0.468)$ & & $0.034(0.474)$ & \\
\hline \multicolumn{6}{|l|}{ Level 2} \\
\hline Deprived neighborhood & & & & $-1.123(0.791)$ & \\
\hline Percentage of elderly & & & & $0.100(0.299)$ & \\
\hline Turnover & & & & $0.158(0.363)$ & \\
\hline Physical disorder & & & & $-0.018(0.372)$ & \\
\hline \multicolumn{6}{|l|}{ Random effects } \\
\hline \multicolumn{6}{|l|}{ Level 1} \\
\hline Constant & $30.262(1.596)^{* * *}$ & $29.312(1.553)^{* * *}$ & $29.441(1.557)^{* * *}$ & $29.319(1.554)^{* * *}$ & \\
\hline \multicolumn{6}{|l|}{ Level 2} \\
\hline Constant & $1.888(0.783)^{*}$ & $1.454(0.679)^{*}$ & $1.563(0.703)^{*}$ & $1.244(0.663)$ & \\
\hline Intraclass correlation & 0.059 & 0.047 & 0.050 & 0.041 & \\
\hline Log likelihood & 4786,232 & 4713,448 & 4736,855 & 4710,668 & \\
\hline$\Delta$ Log likelihood $(\Delta d f)$ & & 72,784 & 49,377 & 75,564 & \\
\hline$P$ & & $<0.001$ & $<0.001$ & $<0.001$ & \\
\hline
\end{tabular}

Note: ${ }^{*} \mathrm{p}<0.05,{ }^{* *} \mathrm{p}<0.01,{ }^{* * *} \mathrm{p}<0.001$.

Model 0: null model without level 1 and level 2 variables; Model 1a: model with only level 1 variables; Model $1 \mathrm{~b}$ : parsimonious model with only level 1 variables; Model 2a: model with level 1 and level 2 variables; Model 2b: parsimonious model with level 1 and level 2 variables.

cohesion but not with other components of neighborhood social capital.

Finally, we found interaction effects between neighborhood deprivation and neighborhood social processes. Previous research suggested that social processes in the neighborhood have a stronger health effect in deprived neighborhoods $[11,20]$. In this study, the interaction between neighborhood attachment and neighborhood deprivation is analyzed. For both social cohesion and informal social control, there was a significant interaction between neighborhood deprivation and neighborhood attachment. Social cohesion and informal social control tend to decline more strongly with decreasing levels of neighborhood attachment for those in deprived neighborhoods than for those in non-deprived neighborhoods.

\section{Limitations}

Apart from the strengths summarized in the introduction, the study also has limitations, opening up avenues for further work. First, the compositional and contextual factors found to be responsible for generating spatial disparities in social capital are specific to the study area at hand and cannot be straightforwardly generalized to other urban contexts in Europe and beyond. Additional empirical evidence, especially from countries with sharper social inequalities, is desirable to help refine our insights into the factors and their interactions that steer the spatial development of neighborhood social capital [24]. Second, the current analysis is static and does not allow examining how social capital evolves over time. Comparing spatial differences of social capital at different points in time would enable evaluating before-after scenarios so as to directly measure the impact of territorial policy initiatives. To this end, researchers may rely on multilevel analyses for repeated measures in time, which will require the estimation of changing neighborhood effects while controlling for changing population composition. Third, because the data used are cross-sectional, reverse causation cannot be 
excluded. The relationship could go from neighborhood social capital to individual and neighborhood variables instead of vice versa [11]. For instance, self-selection may arise in the sense that deprived people are condemned to neighborhoods with low social capital rather than low social capital fostering neighborhood deprivation. Another data limitation is that people who do not speak Dutch have been excluded from the survey. This might have biased the relationship between ethnicity and social capital. Finally, when interpreting the results the reader should be alerted that there is an overlap related to content between neighborhood attachment and each of the social capital components.

Relevance for researchers and practitioners in other contexts While our results are specific to the current case study, they do have wider repercussions for policy strategies seeking to foster neighborhood social capital in other contexts than ours for at least three reasons. First, our study has foregrounded the importance of contextual effects in encouraging neighborhood social capital at the city scale. Furthermore, given the intermediating role of neighborhoodlevel characteristics, it can be anticipated that not all areas within a city will be equally responsive to social capital promoting initiatives. Such initiatives are likely to be more effective when tailored to specific areas. Second, our analysis further shows that not all forms of social capital are influenced by contextual factors to the same extent, implying that changes in neighborhood characteristics are conducive to, say, trust while leaving social support unaffected. Finally, our analysis has demonstrated that complex interrelationships between individual and neighborhood variables exist, which are often overlooked in current work. In particular, neighborhood deprivation seems to amplify or dampen the association between characteristics of neighborhood inhabitants and neighborhood social capital.

\section{Conclusions}

This paper demonstrates that social capital significantly differs across neighborhoods in Ghent. Neighborhood factors partly explain this variation, after individual-level variables are controlled for. This study adds to the modest knowledge base concerning neighborhood differences in social capital. Our findings suggest that health-promoting initiatives to improve social capital should consider neighborhood attachment, neighborhood deprivation and residential turnover. Policy initiatives focussing on these aspects are likely to render neighborhood social capital more equitable across urban regions.

\section{Endnotes}

${ }^{a}$ We have run multilevel models with and without individual income as an explanatory variable. Individual income is positively associated with generalized trust $(\mathrm{p}<0.001)$ but exhibits no significant relationship with the other components of social capital. Adding individual income to the models did impact the estimation of the parameters for the independent variables (with the largest impact on the estimation of the parameters for age and nationality), but did not alter the findings described in this paper. The analyses including individual income are available from the author upon request.

\section{Competing interests}

The authors declare that they do not have competing interests.

\section{Authors' contributions}

TN and W performed the statistical analyses. DDW, TN and W drafted the manuscript. SW coordinated the study. All authors reviewed the manuscript and approved the final version.

\section{Acknowledgements}

Tijs Neutens gratefully acknowledges the financial support by the Research Foundation Flanders (FWO).

\section{Author details}

'Department of Geography, Ghent University, Ghent, Belgium. ${ }^{2}$ Department of Family Medicine and Primary Health Care, Ghent University, Ghent, Belgium. ${ }^{3}$ Research Foundation Flanders, Brussels, Belgium.

Received: 12 August 2013 Accepted: 10 November 2013 Published: 13 November 2013

\section{References}

1. Kawachi I, Berkman LF: Neighborhoods and Health. New York: Oxford University Press; 2003.

2. Carpiano RM: Toward a neighborhood resource-based theory of social capital for health: can Bourdieu and sociology help? Soc Sci Med 2006, 62:165-175.

3. Marmot M, Bell R: Fair society, healthy lives. Public Health 2012, 126:4-10.

4. Kawachi I, Kennedy BP, Lochner K, Prothrow-Stith D: Social capital, income equality, and mortality. Am J Public Health 1997, 87:1491-1498.

5. Diez Roux AV: Residential environments and cardiovascular risk. J Urban Health 2003, 80:569-589.

6. De Silva MJ, McKenzie K, Harpham T, Huttly SR: Social capital and mental illness: a systematic review. J Epidemio/ Community Heal 2005, 59:619-627.

7. Peterson LE, Tsai AC, Petterson S, Litaker DG: Rural-urban comparison of contextual associations with self-reported mental health status. Health Place 2009, 15:125-132.

8. Wen M, Browning CR, Cagney KA: Poverty, affluence, and income inequality: neighborhood economic structure and its implications for health. Soc Sci Med 2003, 57:843-860.

9. Franzini L, Caughy M, Spears W, Fernandez Esquer ME: Neighborhood economic conditions, social processes, and self-rated health in low-income neighborhoods in Texas: a multilevel latent variables model. Soc Sci Med 2005, 61:1135-1150.

10. Portes A: The Two Meanings of Social Capital. Sociol Forum 2000, 15:1-11.

11. De Clercq B, Vyncke V, Hublet A, Elgar FJ, Ravens-Sieberer U, Currie C, Hooghe $M$, leven A, Maes L: Social capital and social inequality in adolescents' health in 601 Flemish communities: A multilevel analysis. Soc Sci Med 2012, 74:202-210.

12. Ziersch AM, Baum FE, Macdougall C, Putland C: Neighbourhood life and social capital: the implications for health. Soc Sci Med 2005, 60:71-86.

13. Folland S: Does "community social capital" contribute to population health? Soc Sci Med 2007, 64:2342-2354.

14. Brown TT, Scheffler RM, Seo S, Reed M: The empirical relationship between community social capital and the demand for cigarettes. Health Econ 2006, 15:1159-1172.

15. Costa-Font J, Mladovsky P: Social capital and the social formation of health-related preferences and behaviours. Health Econ Policy Law 2008, 3:413-427. 
16. Tobler AL, Komro KA, Maldonado-Molina MM: Early adolescent, multi-ethnic, urban youth's exposure to patterns of alcohol-related neighborhood characteristics. J Community Health 2009, 34:361-369.

17. Thorlindsson T, Valdimarsdottir M, Hrafn Jonsson S: Community social structure, social capital and adolescent smoking: a multi-level analysis. Health Place 2012, 18:796-804.

18. Mohnen SM, Völker B, Flap H, Groenewegen PP: Health-related behavior as a mechanism behind the relationship between neighborhood social capital and individual health - a multilevel analysis. BMC Public Health 2012, 12:116.

19. Stafford M, De Silva M, Stansfeld S, Marmot M: Neighbourhood social capital and common mental disorder: testing the link in a general population sample. Health Place 2008, 14:394-405.

20. Vyncke V, De Clercq B, Stevens V, Costongs C, Barbareschi G, Jónsson SH, Curvo SD, Kebza V, Currie C, Maes L: Does neighbourhood social capital aid in levelling the social gradient in the health and well-being of children and adolescents? A literature review. BMC Public Health 2013, 13:65.

21. Ferlander S: The Importance of Different Forms of Social Capital for Health. Acta Sociol 2007, 50:115-128.

22. Moore S, Daniel M, Gauvin L, Dubé L: Not all social capital is good capital. Health Place 2009, 15:1071-1077.

23. Portes A: Social Capital: Its Origins and Applications in Modern Sociology. Annu Rev Sociol 1998, 24:1-24.

24. Eriksson M: Social capital and health - implications for health promotion. Glob Health Action 2011, 4

25. Bourdieu P: The forms of capital. Handb Theory Res Sociol Educ 1986, 241:241-258.

26. Putnam RD: Bowling Alone. The collapse and revival of American community; 2000:541.

27. Putnam RD, Leonardi R, Nanetti R: Making Democracy Work: Civic Traditions in Modern Italy. Princeton: Princeton University Press; 1993:280.

28. Meijer M, Bloomfield K, Röhl J, Grittner U: Do neighborhoods affect individual mortality? A systematic review and meta-analysis of multilevel studies. Soc Sci Med 2012, 74:1204-1212.

29. Roseland M: Sustainable community development: integrating environmental, economic, and social objectives. Prog Plann 2000, 54:73-132.

30. Beugelsdijk S, Van Schaik T: Differences in Social Capital Between 54 Western Regions. Reg Stud 2005, 39:1053-1064.

31. Van Oorschot W, Arts W, Gelissen J: Social Capital in Europe. Acta Sociol 2006, 49:149-167.

32. Hofferth SL, Iceland J: Social capital in rural and urban communities. Rural Sociol 1998, 63:574-598

33. Lannoo S, Verhaeghe P-P, Vandeputte B, Devos C: Differences in Social Capital Between Urban and Rural Environments. J Urban Aff 2012, 34:373-394.

34. Sørensen JFL: Testing the Hypothesis of Higher Social Capital in Rural Areas: The Case of Denmark. Reg Stud 2012, 46:873-891.

35. Lindstrom M, Merlo J, Ostergren PO: Individual and neighbourhood determinants of social participation and social capital: a multilevel analysis of the city of Malmo, Sweden. Soc Sci Med 2002, 54:1779-1791.

36. Subramanian SV, Lochner KA, Kawachi I: Neighborhood differences in social capital: a compositional artifact or a contextual construct? Health Place 2003, 9:33-44.

37. Lindstrom M: Ethnic differences in social participation and social capital in Malmo, Sweden: a population-based study. Soc Sci Med 2005, 60:1527-1546.

38. Veenstra G: Social capital and health (plus wealth, income inequality and regional health governance). Soc Sci Med 2002, 54:849-868.

39. Ichida $Y$, Kondo K, Hirai H, Hanibuchi T, Yoshikawa G, Murata C: Social capital, income inequality and self-rated health in Chita peninsula, Japan: a multilevel analysis of older people in 25 communities. Soc Sci Med 2009, 69:489-499.

40. Wilson JQ, Kelling GL: Broken Windows. Atl Online 1982:1-9.

41. Skogan WG: Disorder and decline: Crime and the spiral of decay in American neighbourhoods. Berkeley, CA: University of California Press; 1990:219.

42. Steenbeek W: Social and physical disorder. How community, business presence and entrepreneurs influence disorder in Dutch neighborhoods. Utrecht: Utrecht University Press; 2011. PhD thesis.

43. Renalds A, Smith TH, Hale PJ: A systematic review of built environment and health. Fam Community Health 2010, 33:68-78.

44. Leyden KM: Social capital and the built environment: The importance of walkable neighborhoods. Am J Public Health 2003, 93:1546-1551.
45. Diez-Roux AV: Multilevel Analysis in Public Health Research. Annu Rev Public Health 2000, 21:171-192.

46. Duncan C, Jones K, Moon G: Context, composition and heterogeneity: using multilevel models in health research. Soc Sci Med 1998, 46:97-117.

47. Diez Roux AV: A glossary for multilevel analysis. J Epidemio/ Community Heal 2002, 56:588-594.

48. Leyland AH, Groenewegen PP: Multilevel modelling and public health policy. Scand J Public Health 2003, 31:267-274

49. Uphoff EP, Pickett KE, Cabieses B, Small N, Wright J: A systematic review of the relationships between social capital and socioeconomic inequalities in health: a contribution to understanding the psychosocial pathway of health inequalities. Int J Equity Health 2013, 12:54.

50. Hardyns W, Vyncke V, Pauwels L, Willems S: The social capital and well-being in neighbourhoods in Ghent (SWING) survey. Ghent, Belgium; 2011:28. https://biblio.ugent.be/publication/4164887.

51. Vandermotten C, Marissal P, Van Hamme G, Kesteloot C, Slegers K, Vanden Broucke L: Dynamische Analyse van de Buurten in Moeilijkheden in de Belgische Stadsgewesten. POD Maatschappelijke Integratie: Grootstedenbeleid Brussel; 2006.

52. Oberwittler D, Wikström POH: Why small is better. Advancing the study of the role of behavioral contexts in crime causation. In Putt crime its place Units Anal Geogr Criminol. Edited by Weisburd D, Bernasco W, Bruinsma GNJ. New York; 2009:33-58

53. Caspall FC, Jenks GF: Error on choroplethic maps: definition, measurement, reduction. Ann Assoc Am Geogr 1971, 61:217-244.

54. Baum FE, Ziersch AM, Zhang G, Osborne K: Do perceived neighbourhood cohesion and safety contribute to neighbourhood differences in health? Health Place 2009, 15:925-934.

55. Subramanian SV, Kim DJ, Kawachi I: Social trust and self-rated health in US communities: a multilevel analysis. J Urban Health 2002, 79:S21-S34.

56. Takagi D, Kawachi I, Ikeda K: Neighborhood social capital and crime victimization: Comparison of spatial regression analysis and hierarchical regression analysis. Soc Sci Med 2012, 1895-1902.

doi:10.1186/1476-072X-12-52

Cite this article as: Neutens et al: Neighborhood differences in social capital in Ghent (Belgium): a multilevel approach. International Journal of Health Geographics 2013 12:52.

\section{Submit your next manuscript to BioMed Central and take full advantage of:}

- Convenient online submission

- Thorough peer review

- No space constraints or color figure charges

- Immediate publication on acceptance

- Inclusion in PubMed, CAS, Scopus and Google Scholar

- Research which is freely available for redistribution

Submit your manuscript at www.biomedcentral.com/submit
C Biomed Central 